\title{
Effect of intervention management care program on improving quality of life outcome among mastectomy women with diabetic: A comparative study
}

\author{
Maha Moussa Mohamed Moussa*1, Fatma Zaki Mohamed Farahat ${ }^{2}$, Nor El-Hoda Mohamed El-Sayed El-Shabory ${ }^{2}$ \\ ${ }^{1}$ Community Health Nursing, Faculty of Nursing, Port Said University, Port Said, Egypt \\ ${ }^{2}$ Maternity, Gynecology and obstetrics, Faculty of Nursing, Port Said University, Port Said, Egypt
}

Received: March 6, 2019

DOI: $10.5430 /$ jnep.v9n9p36

\author{
Accepted: May 13, 2019 \\ Online Published: June 6, 2019 \\ URL: https://doi.org/10.5430/jnep.v9n9p36
}

\begin{abstract}
Objective: This study aimed to evaluate the effect of intervention management care program on improving quality of life outcome among mastectomy women with diabetic.

Subjects and Methods: Design: A quasi-experimental deign was used. Setting: It was selected from two settings Port Said oncology outpatient clinic and Damietta oncology outpatient clinic. Sampling: A purposive sample of mastectomy diagnosed with diabetic. The total sample was 50 women. They were 20 women from Port Said and 30 mastectomy women from Damietta Tools: The study data were collected by using three tools: The first tool-A women Structure interviewing questionnaire Sheet-its consisted of three parts: part one, demographic characteristics; part two, past and present medical history, complications related to diabetes and cancer and obstetrics characteristics; part three, knowledge about diabetes and mastectomy. The second tool-self-reported practices. The third tool-quality of life scale.

Results: The study sample age ranged between 35 to more than 60 years with a mean of (50.3 \pm 8.6 and $48.3 \pm 9.4)$ respectively in Damietta and Port-Said. There was statistically significant positive but strong correlate on among the three variables the strongest being between total scores knowledge and practices $(r=0.466)$ and strongest between knowledge and quality of life $(r$ $=0.367$ ) especially psychological aspects.

Conclusions: The present study concluded that there is a marked gap between knowledge, practice and quality of life among the mastectomy women with diabetic before implement the program. There was an improvement in mastectomy women of all groups' knowledge and practice after the program. Also there were positive changes in quality of life in psychological, spiritual, emotional and social aspects. Furthermore, there were improvement in knowledge practice and positive change in quality of life after the implementation of the program of Damietta group more than port Said group.
\end{abstract}

Key Words: Nursing, Management Care Program, Mastectomy women, Diabetes mellitus

\section{INTRODUCTION}

Breast cancer is one of the most common malignant tumors in women, and is the second leading cause of death among women. ${ }^{[1-3]}$ Approximately one in eight women will be affected by breast cancer during her lifetime, and more than 2.9 million breast cancer survivors currently reside in the United States. ${ }^{[4-6]}$ In Egypt, breast cancer is the most common cancer among women, representing $18.9 \%$ of total cancer cases (35.1\% in women and $2.2 \%$ in men). In addition, the Egypt National Cancer Institute (NCI) series 10,556 patients dur-

\footnotetext{
*Correspondence: Maha Moussa Mohamed Moussa; Email: mahamoussa10@yahoo.com; Address: Community Health Nursing, Faculty of Nursing, Port Said University, Port Said, Egypt.
} 
ing the years of 2012 with an age adjusted rate of 49.6 per $1,000,000$ population. ${ }^{[2,6]}$

Many factors have been associated with an increased risk of breast cancer demographics, personal history of benign or malignant breast diseases, family history, exposure to radiation and genetic predisposition and environmental factors such as high fat diet accompanied with sedentary life style constitute increased breast cancer risk. Thus, metabolic abnormalities including obesity and type 2 diabetes (T2DM) are positively associated with the breast cancer risk. Diabetic condition induces changes in several hormonal systems, including insulin, insulin like growth factors and estrogens that may affect the breast cancer risk. ${ }^{[7,8]}$ In addition the long-term of T2DM effects include loss of vision, kidney problems, heart disease, and nerve damage. Cancer is also an under-appreciated long-term risk resulting from obesity. ${ }^{[7,9,10]}$

Diabetes mellitus is a serious and growing health problem worldwide. Diabetes mellitus has a predicted increase in global prevalence of $69 \%$ and $20 \%$ in developing and developed countries, respectively, between 2010 and 2030, thereby depicting a growing burden of this disease. ${ }^{[11,12]}$ Type 2 diabetes accounts for $90 \%-95 \%$ of all diagnosed cases of diabetes 2 and is characterized by insulin resistance and hyperinsulinemia in the early phases of the disease. ${ }^{[7]}$ It has been hypothesized that hyperinsulinemia may increase the risk of breast cancer through direct effects on breast tissue or indirectly by increasing circulating concentrations of estrogens, testosterone and insulin-like growth factors. ${ }^{[9,10]}$ Thus, Diabetes has been related to an elevated risk of several cancers. ${ }^{[11,12]}$

Quality of life (QOL) is one of the important concepts not to be forgotten for cancer patients during their lives, and throughout their curative and/or palliative treatments. World Health Organization are defines quality of life as multidimensional construct that refers to 'individuals' perception of their position in life within the whole context of the culture and value systems of the social environment in which they live and in relation to their goals, expectations, standards and concerns. ${ }^{[13-15]}$ A number of factors influencing the QOL in women with breast cancer have been identified as personal factors, optimism, social support, symptom distress, medical characteristics, appraisal of illness and coping strategies. ${ }^{[16,17]}$

Many dimensional should be considered in the measurement of quality of life including physical and psychological health, level of independence, social relationships, environment, and the spiritual domain. ${ }^{[18,19]}$ 'The functional capacity' refers to the ability to perform daily living activities, and the level of physical activity. "Social function" indicate the ability of an individual to interact with other members of family, friends, and other people, while "emotional function" refers the level of anxiety induced by side effects developed as a result of treatments applied, and disease-related symptoms as pain. ${ }^{[19,20]}$

Breast cancer is becoming more prevalent worldwide and the associated intervention nursing care is becoming more complex. Nurses are at the forefront of both the prevention and management of mastectomy and are critical to women education and the minimization of complications. Nurses across a wide range of healthcare settings have a key role in managing mastectomy. The mastectomy women can experience long-term complications. Those complications can be seen through medical, physical, psychological, even psychosocial and diminished of their quality of life. The intervention of mastectomy women and their families to acquire basic knowledge about the disease and treatment, facilitated communication with the multidisciplinary team, and helped the women to prepare themselves for the potential upcoming difficulties. Although community health nurse play a unique and important role in improving and assisting quality of life outcome among mastectomy women's with diabetes. ${ }^{[17,19]}$

\subsection{Significance of the study}

The main objectives of intervention management of mastectomy women are to improve the quality of life of women so that they can have a normal life as far as possible. Successful intervention management depends upon the extent to which a woman's behavior, in terms of keeping appointments, taking medication and making life style changes coincides with medical advice given. Therefore; all mastectomy women need ongoing access to quality intervention management of this complex chronic illness and improving quality of life. Many researchers have dealt with the treatment of mastectomy or diabetes only focusing on its care and consequences. Scarce research has addressed this issue, so this study aim to evaluate the effect of intervention management program on improving quality of life outcome among mastectomy women with diabetes.

\subsection{Aim of the study}

This study aimed to evaluate the effect of intervention management care program on improving quality of life outcome among mastectomy women with diabetes.

\subsection{Objectives}

(1) Assess the knowledge and of mastectomy women with diabetic.

(2) Assess the women Self -reported practices of mastectomy women with diabetic. 
(3) Design intervention management care program of mastectomy women with diabetic.

(4) Implement the intervention program for women after mastectomy.

(5) Compare between Damietta and Port Said cites regarding Knowledge, practices and quality of life in before and after program among mastectomy women with diabetes.

(6) Evaluate the effectiveness of women management on improving quality of life outcome.

\subsection{Research hypotheses}

The intervention management care program has a positive effect on women's quality of life (mastectomy women with diabetes).

\section{SUBJECTS AND METHODS}

\subsection{Technical design}

Include description of the research design used, the study setting, the subjects, and the tools of data collection.

\subsection{Research design}

Design: A quasi-experimental deign was used.

\subsection{Setting}

This study was carried out in the two cities (Port Said oncology outpatient clinics and Damietta Oncology outpatient clinic). This interactional research was accomplished at two randomly selected Port Said oncology outpatient clinics and Damietta Oncology outpatient clinic Egypt. These outpatients were the largest out patients in oncology at both cities, so they have large population densities. In addition, they are attended by women with similar socioeconomic status, which guarantees the homogeneity of the study sample.

\subsection{Sample}

A purposive sampling technique was used in collecting data. The subjects of this study were women suffering from diabetes mellitus and completed radical mastectomy. The researcher approached women during their follow up. The total sample was 50 mastectomy women with diabetes. They were 20 women in Port Said and 30 women in Damietta. During selecting a sample equal from the pervious to cities, but ten women from Port Said outpatient clinic withdraw from the sample is not available.

\subsection{Inclusion criteria}

Middle aged women (35 - $\geq 60$ years) Diagnosed women with diabetes mellitus and completed radical mastectomy.

\subsection{Tools of data collection}

Based on the recent and scientific research. Data was collected by the following three tools:

The first tool: A women structure interviewing questionnaire Sheet: to assess the knowledge it's consisted of three parts: part one: demographic characteristics; part two: past and present medical history, complications related to diabetes and cancer and obstetrics characteristics; part three: knowledge about diabetes and mastectomy.

The first part: This part contains demographic characteristics of the mastectomy women; it including the name, age, level of education, occupation, marital status, residence, income and crowding index.

The second part: This part contains past and present medical history and obstetrics characteristics of mastectomy women; it includes type of treatment, health status after using treatment, present side effects and complications, chronic diseases, duration since mastectomy, duration of menstruation, regularity of menstruation, age at last of menstruation and amount of bleeding during menstruation. It's composed of 12 questions.

The third part: This part related to knowledge of studied sample including questions about mothers' knowledge diabetes and mastectomy definition, signs and symptoms, precipitating factors, warning signs, factors effecting on health, and complications of disease, type of therapy after surgery, women condition after medications, compliance and medications side effect. The scores of items ranged as: the complete and correct answer takes 2 score and the incomplete correct response takes 1 score. The total questions were 26 and the total score (52). The women knowledge was considered $(31.2 \%)$ score equal $60 \%$ was correct answer, while less than $60 \%$ incorrect answer.

The second tool: Women self-reported practices questions about self-care practices this including care of skin and nail, care of hands and under armpit, care of the feet, bathing and daily activities. The total questions number was 49 . The practice accepted score of self-care practices was considered (44.1\%) score equal $60 \%$ was accepted while less than $60 \%$ not accepted.

The third tool: A quality of life scale was adapted by the researchers and based on World health organization (WHO, 1996), ${ }^{[21,22]}$ it was the purposed assessing the quality of life for mastectomy women with diabetic. It was divided into six dimensions: physical, psychological, emotional and social, sexual and spiritual and moral. It contains 33 questions, including of physical health (7 questions), psychological, spiritual and moral (12 questions) emotional/social relation- 
ships (8 questions), and sexual (6 questions). A final score is produced by normalizing it to a standard scale of (0-10). The total score was high quality of life was more $50 \%$, while Poor quality of life was less than $50 \%$.

\subsection{Intervention management care program}

Intervention management care program was developed by the researchers after reviewing of scientific research and review of literature ${ }^{[23,24]}$ and also after assessment phase and defined needs and problems of study women the intervention management care program was a simple Arabic language.

\subsubsection{The objective of the program}

The objective of the program was to effect of intervention management care program on improving quality of life outcome among mastectomy women with diabetic. A review of advanced national and international related literature guideline and available published information using books, articles, magazines, video and internet to develop the data of the program.

\subsubsection{Assessment phase (pretest)}

Based on knowledge and information was collected study women in initial phase the intervention management care program was designed by the researchers after reviewing the scientific review of literature, ${ }^{[25,26]}$ also in these phase assess women's knowledge and problems and identify needs and problems according to practice mastectomy women with diabetes.

\subsubsection{Implementation phase}

(Management program) implemented by using different teaching methods as small lecture, group discussion, role playing, demonstration, and re-demonstration were used. Also different audio visual materials were used as pamphlets; hand out, pictures, video film, and posters to facilitate the teaching of each topic. In addition equipment such as soaps, wipes or handkerchiefs, if the classrooms without the basin for skin care, the researchers uses small basin and clean water.

\subsubsection{Evaluation phase (posttest)}

This phase including evaluating and comparing the effectiveness of intervention management care program immediately after implementation of the program by used post-test tools.

\subsubsection{Validity and reliability}

The interview questionnaire sheet was constructed after review of related literature, and revised by five experts in the field community health nursing and obstetrics health nursing to test content validly and applicability. Recommended modifications were done. The questionnaire was compiled in Arabic, translated into English. Adequately-translated questions were important in this study into Arabic because the first language of most of the study population.

\subsubsection{Pilot study}

A pilot study was carried out on 5\% (3 women) of the study sample to test tools for clarity, applicability and the time required to filling in the tools. The results of the pilot indicated that some questions were not clear and enough and concise. Data obtained from the pilot study were analyzed and accordingly the necessary modifications on the study tools were done those who participated in the pilot study results were excluded from the study sample.

\subsubsection{Field work}

The women were divided into 2 groups Port Said and Damietta oncology clinic. The group of the Port Said subdivided into two groups and the group Damietta subdivided into three groups each group, including (10 patients small group) and implementation of the program was done for each group separately. The program was implemented over 12 sessions (3 theoretical, 9 practice). The program was implemented over 6 weeks period, 2 hours per week. Each session ranged between 1-2 hours. Each group according to their available times and place for attendance which commonly in the morning between 10.00 AM until 12 AM, it started. The first 3 sessions (knowledge) took about one hour in each session. A presentation focus upon the concept of diabetes about definition, signs and symptoms, precipitating factors, warning signs, factors effecting on health, complications, mastectomy type of therapy after surgery, patients condition after medications, effect of treatment, patient opinion about compliance and medications side effect, the second session included (practices) took about 1.5-2 hours in each session. This focus on skills the methods of care for skin and nail, care of hands and arms, care of the feet and daily household activities and how to apply in the home, methods of drying of hand and how to clip the nails the end of each session, the researcher ensured the patients understanding of the instructions. Teaching methods and aids used as pamphlets; hand out, pictures, and posters to facilitate the teaching of each topic. In addition equipment such as soaps, wipes or handkerchiefs. The effectiveness of intervention management care program immediately after implementation of the program by used post-test tools. The questionnaire was filled out by the researchers. The study was conducted over a period of 12 months beginning at January 2016 till the end of December 2017.

\subsection{Ethical consideration}

The aim of the study explained to the directors of oncology clinics in both Port Said and Damietta to take their permission to conduct this study. Also, explaining the aim of the 
study to each participant women to gain confidentiality, cooperation and explain the importance to the participation.

\subsection{Administrative design}

An official permission was obtained from the directors of the oncology clinics in the Port Said and Damietta cities through official a formal letters from the dean of the Faculty of Nursing, Port Said University. Participants were reassured about the strict confidentiality of any obtained information.

\subsection{Statistical analysis of the data}

The Statistical Package for the Social Sciences (SPSS, version 16.0) was used for data analysis. Descriptive statistics were employed to summarize the demographic data, which was presented using frequency tables and expressed as percentages, means, and standard deviations. The chisquare and Fisher exact test were used to determine if any associations existed between mastectomy women and sociodemographic variables. Mc Nemar test is used for data of the two groups coming from the same participants and analyzes tests performed before and after treatment in a population.
Statistically significance was considered at $p$-value $<.05$. pearson correlation analysis was used for assessment of the interrelationship among scores of knowledge, practices and quality of life.

\section{RESUlts}

Table 1 shows the demographic characteristics of the studied sample. It was found that the study sample age ranged between 35 to more than 60 years with a mean of $(50.3 \pm$ 8.6 and $48.3 \pm 9.4$ ) respectively in Damietta and Port-Said.

About more two thirds $(73.3 \%)$ respectively in Damietta group, while slightly less than two thirds (55\%) in Port Said group were married. According to occupation, $86.7 \%$ of the subjects in the Damietta group were housewife, while slightly less than two third $(55 \%)$ in Port Said group were working. Also the table revealed that $60 \%$ \& $45 \%$ of respectively in Damietta and Port-Said were enough, and also crowding index ranged from 1 to 2 or more per room the mean of $1.7 \pm 0.7$ in Damietta group compare to $2.2 \pm 0.7$ Port Said group.

Table 1. Demographic characteristics of the studied groups of women with mastectomy from Damietta and Port Said general hospitals

\begin{tabular}{|c|c|c|c|c|c|}
\hline \multirow{2}{*}{ Demographic characteristics } & \multicolumn{2}{|c|}{ Damietta group $(\mathrm{n}=30)$} & \multicolumn{2}{|c|}{ Port Said group $(n=20)$} & \multirow{2}{*}{ Significance } \\
\hline & No. & $\%$ & No. & $\%$ & \\
\hline \multicolumn{6}{|l|}{ Age (years) } \\
\hline $35-$ & 4 & 13.3 & 2 & 10.0 & \multirow{6}{*}{$t=.785 ; p=.436$} \\
\hline $40-$ & 11 & 36.7 & 12 & 60.0 & \\
\hline $50-$ & 10 & 33.3 & 3 & 15.0 & \\
\hline 60 & 5 & 16.7 & 3 & 15.0 & \\
\hline Min-Max & 35.0 & & 35.0 & & \\
\hline Mean \pm SD & 50.3 & & 48.3 & & \\
\hline \multicolumn{6}{|l|}{ Educational level } \\
\hline cannot read and write & 10 & 33.3 & 6 & 30.0 & \multirow{5}{*}{$\chi^{2}=2.431 ;{ }^{\mathrm{MC}} p=.682$} \\
\hline Read and write & 8 & 26.7 & 4 & 20.0 & \\
\hline Basic education & 4 & 13.3 & 1 & 5.0 & \\
\hline Secondary education & 6 & 20.0 & 6 & 30.0 & \\
\hline University education & 2 & 6.7 & 3 & 15.0 & \\
\hline \multicolumn{6}{|l|}{ Marital status } \\
\hline Married & 22 & 73.3 & 11 & 55.0 & \multirow[t]{2}{*}{$\chi^{2}=1.800 ; p=.180$} \\
\hline Not married & 8 & 26.7 & 9 & 45.0 & \\
\hline \multicolumn{6}{|l|}{ Occupation } \\
\hline Working & 4 & 13.3 & 11 & 55.0 & \multirow[t]{2}{*}{$\chi^{2}=9.921 ; p=.002 *$} \\
\hline Housewife & 26 & 86.7 & 9 & 45.0 & \\
\hline \multicolumn{6}{|l|}{ Income } \\
\hline Enough & 18 & 60.0 & 9 & 45.0 & \multirow{3}{*}{$\chi^{2}=5.0 ;{ }^{\mathrm{MC}} p=.085$} \\
\hline Not enough & 12 & 40.0 & 8 & 40.0 & \\
\hline More than enough & 0 & 0.0 & 3 & 15.0 & \\
\hline \multicolumn{6}{|l|}{ Crowding index } \\
\hline Less than 1 & 3 & 10.0 & 0 & 0.0 & \multirow{5}{*}{$t=2.408 ; p=.020^{*}$} \\
\hline $1-<2$ & 13 & 43.3 & 3 & 15.0 & \\
\hline 2 or more & 14 & 46.7 & 17 & 85.0 & \\
\hline Min-Max & \multicolumn{2}{|c|}{$0.2-3.5$} & \multicolumn{2}{|c|}{$1.0-4.0$} & \\
\hline Mean \pm SD & \multicolumn{2}{|c|}{$1.7 \pm 0.7$} & \multicolumn{2}{|c|}{$2.2 \pm 0.7$} & \\
\hline
\end{tabular}


Table 2 illustrates Comparison between the Damietta and Port Said groups according to medical and obstetrics characteristics, it was noticed that there was no statistically significant changes could be detected in either of the two groups, regardless type of treatment the Damietta groups $50 \%$ were chemical compared to Port Said groups 50\% were both. As regarding the health status after using treatment the Damietta groups 50\% were very improved compared to Port Said groups 50\% were moderate improvement. Table 2 also shows that, at the side effects and complications the Damietta groups $90 \%$ having the complications compared to Port Said groups were 75\% chronic disease in Damietta groups $97 \%$ were having diseases while Port Said groups were $90 \%$.

Table 2. Medical and obstetrics characteristics of the studied female patients with mastectomy from Damietta and Port Said general hospitals

\begin{tabular}{|c|c|c|c|c|c|}
\hline \multirow{2}{*}{ Medical and obstetrics characteristics } & \multicolumn{2}{|c|}{ Damietta G. Hospitals $(n=30)$} & \multicolumn{2}{|c|}{ Port said hospital $(n=20)$} & \multirow{2}{*}{ Significance } \\
\hline & No. & $\%$ & No. & $\%$ & \\
\hline \multicolumn{6}{|l|}{ Type of treatment } \\
\hline Chemical & 15 & 50.0 & 4 & 20.0 & \multirow{4}{*}{$\begin{array}{l}\chi^{2}=6.683 \\
{ }^{\mathrm{MC}} p=.061\end{array}$} \\
\hline Radioactivity & 13 & 43.3 & 6 & 30.0 & \\
\hline Both & 1 & 3.3 & 10 & 50.0 & \\
\hline Hormonal & 1 & 3.3 & 0 & 0.0 & \\
\hline \multicolumn{6}{|l|}{ Health status after using treatment } \\
\hline Very improved & 15 & 50.0 & 7 & 35.0 & \multirow{3}{*}{$\begin{array}{l}\chi^{2}=1.145 \\
{ }^{\mathrm{MC}} p=.581\end{array}$} \\
\hline Moderate improvement & 11 & 36.7 & 10 & 50.0 & \\
\hline No improvement & 4 & 13.3 & 3 & 15.0 & \\
\hline \multicolumn{6}{|l|}{ Present Side effects and complications } \\
\hline Yes & 27 & 90.0 & 15 & 75.0 & \multirow[t]{2}{*}{${ }^{\mathrm{FE}} p=.239$} \\
\hline No & 3 & 10.0 & 5 & 25.0 & \\
\hline \multicolumn{6}{|l|}{ Having another chronic diseases } \\
\hline Yes & 29 & 97.0 & 18 & 90.0 & \multirow[t]{2}{*}{$p=.020^{*}$} \\
\hline No & 1 & 3.0 & 2 & 10.0 & \\
\hline \# Chronic diseases & $(\mathrm{n}=29)$ & & $(\mathrm{n}=18)$ & & \\
\hline Heart disease & 2 & 6.9 & 3 & 16.7 & ${ }^{\mathrm{FE}} p=.357$ \\
\hline Hypertension & 27 & 93.1 & 14 & 77.8 & ${ }^{\mathrm{FE}} p=.185$ \\
\hline Chest crisis & 17 & 58.6 & 7 & 38.9 & $p=.188$ \\
\hline Anemia & 0 & 0.0 & 4 & 22.2 & ${ }^{\mathrm{FE}} p=.017 *$ \\
\hline Arthritis & 8 & 27.6 & 9 & 50.0 & $p=.120$ \\
\hline \multicolumn{6}{|l|}{ Duration since mastectomy (years) } \\
\hline Less than 1 & 4 & 13.3 & 3 & 15.0 & \multirow{3}{*}{$\begin{array}{l}\chi^{2}=3.650 \\
{ }^{\mathrm{MC}} p=.161\end{array}$} \\
\hline $1-<5$ & 16 & 53.3 & 15 & 75.0 & \\
\hline $5-\leq 10$ & 10 & 33.3 & 2 & 10.0 & \\
\hline \multicolumn{6}{|l|}{ Age of menstruation (years) } \\
\hline $9-10$ & 0 & 0.0 & 6 & 30.0 & \multirow{6}{*}{$\begin{array}{l}t=6.157 \\
p<.0001 *\end{array}$} \\
\hline $11-12$ & 9 & 30.0 & 13 & 65.0 & \\
\hline $13-14$ & 15 & 50.0 & 1 & 5.0 & \\
\hline $15-$ & 6 & 20.0 & 0 & 0.0 & \\
\hline Min-Max & \multicolumn{2}{|l|}{$11.0-17.0$} & \multicolumn{2}{|l|}{$9.0-14.0$} & \\
\hline Mean $\pm \mathrm{SD}$ & $13.4 \pm 1.4$ & & $11.1 \pm 1.2$ & & \\
\hline \multicolumn{6}{|l|}{ Duration of menstruation (days) } \\
\hline $1-<3$ & 2 & 6.7 & 4 & 20.0 & $\chi^{2}=7.422$ \\
\hline $3-<5$ & 17 & 56.7 & 15 & 75.0 & ${ }^{\mathrm{MC}} p=.028^{*}$ \\
\hline $5-$ & 11 & 36.7 & 1 & 5.0 & \\
\hline Amount of bleeding during menstruati & & & & & \\
\hline Menorraghia & 12 & 40.0 & 2 & 10.0 & $\chi^{2}=5.599$ \\
\hline Normal & 15 & 50.0 & 16 & 80.0 & ${ }^{\mathrm{MC}} p=.050 *$ \\
\hline Small amount & 3 & 10.0 & 2 & 10.0 & \\
\hline Regularity of menstruation & & & & & \\
\hline Regular & 21 & 70.0 & 17 & 85.0 & ${ }^{\mathrm{FE}} p=.317$ \\
\hline Irregular & 9 & 30.0 & 3 & 15.0 & \\
\hline Receive treatment for irregularity & $(\mathrm{n}=9)$ & & $(n=3)$ & & \\
\hline Yes & 0 & 0.0 & 1 & 33.3 & ${ }^{\mathrm{FE}} p=.250$ \\
\hline No & 9 & 100.0 & 2 & 66.7 & \\
\hline Age at last menstruation (years) & & & & & \\
\hline $30-$ & 5 & 16.7 & 6 & 30.0 & \\
\hline $40-$ & 15 & 50.0 & 9 & 45.0 & \\
\hline $50-<60$ & 10 & 33.3 & 5 & 25.0 & \\
\hline Min-Max & $31.0-52.0$ & & $31.0-56.0$ & & $t=.899$ \\
\hline Mean $\pm \mathrm{SD}$ & $42.6 \pm 5.4$ & & $44.3 \pm 6.9$ & & $p=.374$ \\
\hline
\end{tabular}


Women's knowledge throughout the comparison between after surgery, women condition after medications, effect of Damietta and Port Said about radiation and chemotherapy treatment, women opinion about compliance and medications among the intervention management mastectomy women side effect. Table 3 also demonstrates that that improvement after the program is illustrated in Table 3. Statistically sig- in knowledge among Damietta group compared to Port Said nificant improvement are noticed in the definition, signs and symptoms, precipitating factors, warning signs, factors efgroup, the highly statically significant and improvement in fecting on health, complications, mastectomy type of therapy

Table 3. Comparison between Damietta and Port Said regarding Knowledge about radiation and chemotherapy among the mastectomy women after the program

\begin{tabular}{|c|c|c|c|c|c|c|c|c|c|c|c|c|}
\hline \multirow{3}{*}{$\begin{array}{l}\text { Knowledge about } \\
\text { cancer and diabetes }\end{array}$} & \multicolumn{4}{|c|}{ Pre-program } & \multirow{3}{*}{ Sig } & \multicolumn{4}{|c|}{ Post-program } & \multirow{3}{*}{ Sig } & \multirow{3}{*}{$\begin{array}{l}\wedge \text { Sig } \\
\text { Damietta } \\
\text { pre/post }\end{array}$} & \multirow{3}{*}{$\begin{array}{l}\wedge \text { Sig } \\
\text { Port } \\
\text { Said } \\
\text { pre/post }\end{array}$} \\
\hline & \multicolumn{2}{|c|}{$\begin{array}{l}\text { Damietta } \\
(\mathrm{n}=30)\end{array}$} & \multicolumn{2}{|c|}{$\begin{array}{l}\text { Port Said } \\
(n=20)\end{array}$} & & \multicolumn{2}{|c|}{$\begin{array}{l}\text { Damietta } \\
(\mathrm{n}=30)\end{array}$} & \multicolumn{2}{|c|}{$\begin{array}{l}\text { Port Said } \\
(\mathrm{n}=20)\end{array}$} & & & \\
\hline & No. & $\%$ & No. & $\%$ & & No. & $\%$ & No. & $\%$ & & & \\
\hline \multicolumn{13}{|c|}{ Definition diabetes and cancer } \\
\hline Incorrect/don't know & 25 & 83.3 & 13 & 65.0 & ${ }^{\mathrm{FE}} p=.164$ & 1 & 3.3 & 4 & 20.0 & ${ }^{\mathrm{FE}} p=.143$ & $p<.0001^{*}$ & $p=.004^{*}$ \\
\hline Correct & 5 & 16.7 & 7 & 35.0 & & 29 & 96.7 & 16 & 80.0 & & & \\
\hline \multicolumn{13}{|c|}{ Signs and symptoms and warning signs } \\
\hline Incorrect & 28 & 93.3 & 15 & 75.0 & ${ }^{\mathrm{FE}} p=.06$ & 11 & 36.7 & 18 & 90.0 & $p<.0001^{*}$ & $p<.0001 *$ & $p=.71$ \\
\hline Correct & 2 & 6.7 & 5 & 25.0 & & 19 & 63.3 & 2 & 10.0 & & & \\
\hline \multicolumn{13}{|c|}{ Precipitating factors and factors effecting on health } \\
\hline Incorrect/don't know & 17 & 56.7 & 16 & 80.0 & $p=.077$ & 5 & 16.7 & 7 & 35.0 & $p=.001 *$ & $p<.0001 *$ & $p=.020^{*}$ \\
\hline Correct & 13 & 43.3 & 4 & 20.0 & & 25 & 83.3 & 13 & 65.0 & & & \\
\hline \multicolumn{13}{|c|}{ Complications and women condition after medications } \\
\hline Incorrect & 17 & 56.7 & 15 & 75.0 & $p=.714$ & 4 & 13.3 & 5 & 25.0 & $p<.0001^{*}$ & $p<.0001 *$ & $p=.311$ \\
\hline Correct & 12 & 40.0 & 5 & 25.0 & & 26 & 86.7 & 15 & 75.0 & & & \\
\hline \multicolumn{13}{|l|}{ Effect of treatment } \\
\hline Incorrect & 19 & 63.3 & 8 & 40.0 & $p=.115$ & 10 & 33.3 & 2 & 10.0 & ${ }^{\mathrm{FE}} p=.091$ & $p=.020^{*}$ & $p=.028^{*}$ \\
\hline Correct & 11 & 36.7 & 12 & 60.0 & & 20 & 66.7 & 18 & 90.0 & & & \\
\hline \multicolumn{13}{|c|}{ Women opinion about compliance and medications side effect } \\
\hline Incorrect & 22 & 73.3 & 11 & 55.0 & $p=.140$ & 2 & 6.7 & 10 & 50.0 & $p<.0001^{*}$ & $p<.0001 *$ & $p=.527$ \\
\hline Correct & 8 & 26.7 & 9 & 45.0 & & 28 & 93.3 & 10 & 50.0 & & & \\
\hline \multicolumn{13}{|c|}{ Definition of radiotherapy } \\
\hline Incorrect/don't know & 25 & 83.3 & 13 & 65.0 & ${ }^{\mathrm{FE}} p=.182$ & 1 & 3.3 & 4 & 20.0 & ${ }^{\mathrm{FE}} p=.143$ & $p<.0001 *$ & $p=.004^{*}$ \\
\hline Correct & 5 & 16.7 & 7 & 35.0 & & 29 & 96.7 & 16 & 80.0 & & & \\
\hline \multicolumn{13}{|c|}{ Effect of radiotherapy after mastectomy } \\
\hline Incorrect & 28 & 93.3 & 19 & 95.0 & ${ }^{\mathrm{FE}} p=1.0$ & 11 & 36.7 & 18 & 90.0 & $p<.0001^{*}$ & $p<.0001^{*}$ & $p=1.0$ \\
\hline Correct & 2 & 6.7 & 1 & 5.0 & & 19 & 63.3 & 2 & 10.0 & & & \\
\hline \multicolumn{13}{|c|}{ Definition of chemotherapy } \\
\hline Incorrect/don't know & 22 & 73.3 & 11 & 55.0 & $p=.180$ & 5 & 16.7 & 9 & 45.0 & $p=.029 *$ & $p<.0001^{*}$ & $p=.527$ \\
\hline Correct & 8 & 26.7 & 9 & 45.0 & & 25 & 83.3 & 11 & 55.0 & & & \\
\hline \multicolumn{13}{|c|}{ Effect of chemotherapy after mastectomy } \\
\hline Incorrect & 17 & 56.7 & 15 & 75.0 & $p=.815$ & 4 & 13.3 & 12 & 60.0 & $p<.0001^{*}$ & $p<.0001 *$ & $p=.311$ \\
\hline Correct & 12 & 40.0 & 5 & 25.0 & & 26 & 86.7 & 8 & 40.0 & & & \\
\hline \multicolumn{13}{|c|}{ Food items that should be taken after mastectomy } \\
\hline Incorrect & 19 & 63.3 & 8 & 40.0 & $p=.105$ & 10 & 33.3 & 2 & 10.0 & ${ }^{\mathrm{FE}} p=.091$ & $p=.020^{*}$ & $p=.028^{*}$ \\
\hline Correct & 11 & 36.7 & 12 & 60.0 & & 20 & 66.7 & 18 & 90.0 & & & \\
\hline Food items that shou & avoic & d after & 1astec & my & & & & & & & & \\
\hline Incorrect & 22 & 73.3 & 11 & 55.0 & $p=.180$ & 5 & 16.7 & 9 & 45.0 & $p=.029 *$ & $p<.0001 *$ & $p=.527$ \\
\hline Correct & 8 & 26.7 & 9 & 45.0 & & 25 & 83.3 & 11 & 55.0 & & & \\
\hline Total knowledge sco & & & & & & & & & & & & \\
\hline Incorrect $(<60 \%$ & 26 & 86.7 & 17 & 85.0 & ${ }^{\mathrm{FE}} p=.454$ & 7 & 23.3 & 15 & 75.0 & $p<.0001^{*}$ & $p<.0001 *$ & $p=.695$ \\
\hline Correct $(\geq 60 \%)$ & 4 & 13.3 & 3 & 15.0 & & 23 & 76.7 & 5 & 25.0 & & & \\
\hline
\end{tabular}


Table 3 also shows the comparison between Damietta and Port Said regarding Knowledge about radiation and chemotherapy among the intervention management women after the program is illustrated in Table 3 the statistically significant improvement are noticed in in all areas in pre and post program in the Damietta groups compare to port Said groups However total score of knowledge in pretest correct answer among Damietta group and Port Said group were $13.3 \%$ and $15.0 \%$ respectively after the program they improved among Damietta group and Port Said was $67.7 \%$ and $25 \%$ respectively. Table 3 also indicated that improvement in knowledge among Damietta group compared to Port Said group, the highly statically significant and improvement in posttest $p<.0001$.
Table 4 demonstrates the changes in women practices throughout the program phase. Table 4 shows there are a was highly statistically significant were reported between pre and post program and $t$ improvement in skin care, hands care, foot care, daily activity in Damietta group than port said group. The total score of practices in pretest accept among Damietta group and Port Said group were $13.3 \%$ and $30 \%$ respectively after the program they improved among Damietta group and Port Said was $86.7 \%$ and $60 \%$ respectively. In this table also indicated that improvement in practices among Damietta group compared to Port Said group, And also there was high statistically significant improvement in posttest $p<$ .0001 .

Table 4. Comparison between pre, and post educational program regarding mastectomy women compliance of practice comprehensive care

\begin{tabular}{|c|c|c|c|c|c|c|c|c|c|c|c|c|}
\hline \multirow{3}{*}{ Practices } & \multicolumn{4}{|c|}{ Pre-Program } & \multirow{3}{*}{ Sig. } & \multicolumn{4}{|c|}{ Post-Program } & \multirow{3}{*}{ Sig. } & \multirow{3}{*}{$\begin{array}{l}\wedge \text { Sig } \\
\text { Damietta } \\
\text { pre/post }\end{array}$} & \multirow{3}{*}{$\begin{array}{l}\wedge \text { Sig } \\
\text { Port Said } \\
\text { pre/post }\end{array}$} \\
\hline & \multicolumn{2}{|c|}{$\begin{array}{l}\text { Damietta } \\
(n=30)\end{array}$} & \multicolumn{2}{|c|}{$\begin{array}{l}\text { Port Said } \\
(n=20)\end{array}$} & & \multicolumn{2}{|c|}{$\begin{array}{l}\text { Damietta } \\
(\mathrm{n}=30)\end{array}$} & \multicolumn{2}{|c|}{$\begin{array}{l}\text { Port Said } \\
(n=20)\end{array}$} & & & \\
\hline & No. & $\%$ & No. & $\%$ & & No. & $\%$ & No. & $\%$ & & & \\
\hline \multicolumn{13}{|c|}{ Skin care practices } \\
\hline Not accept & 24 & 80.0 & 16 & 80.0 & ${ }^{\mathrm{FE}} p=1.0$ & 1 & 3.3 & 4 & 20.0 & ${ }^{\mathrm{FE}} p=.143$ & $p<.0001 *$ & $p<.0001^{*}$ \\
\hline accept & 6 & 20.0 & 4 & 20.0 & & 29 & 96.7 & 16 & 80.0 & & & \\
\hline \multicolumn{13}{|c|}{ Hand care practices } \\
\hline Not accept & 28 & 93.3 & 10 & 50.0 & $p=.026^{*}$ & 24 & 80.0 & 9 & 45.0 & $p<.0001^{*}$ & $p=.254$ & $p=.752$ \\
\hline accept & 2 & 6.7 & 10 & 50.0 & & 6 & 20.0 & 11 & 55.0 & & & \\
\hline \multicolumn{13}{|c|}{ Foot care practices } \\
\hline Not accept & 21 & 70.0 & 11 & 55.0 & $p=.279$ & 5 & 16.7 & 6 & 30.0 & ${ }^{\mathrm{FE}} p=.311$ & $p<.0001 *$ & $p=.110$ \\
\hline accept & 9 & 30.0 & 9 & 45.0 & & 25 & 83.3 & 14 & 70.0 & & & \\
\hline \multicolumn{13}{|c|}{ Bathing and daily activity } \\
\hline Not accept & 17 & 56.7 & 16 & 80.0 & $p=.088$ & 2 & 6.7 & 10 & 50.0 & ${ }^{\mathrm{FE}} p=.001 *$ & $p<.0001^{*}$ & $p=.047^{*}$ \\
\hline accept & 13 & 43.3 & 4 & 20.0 & & 28 & 93.3 & 10 & 50.0 & & & \\
\hline \multicolumn{13}{|c|}{ Total practices score } \\
\hline Not accept & 26 & 86.7 & 14 & 70.0 & ${ }^{\mathrm{FE}} p=.171$ & 4 & 13.3 & 8 & 40.0 & ${ }^{\mathrm{FE}} p=.044 *$ & $p<.0001^{*}$ & $p=.057$ \\
\hline accept & 4 & 13.3 & 6 & 30.0 & & 26 & 86.7 & 12 & 60.0 & & & \\
\hline
\end{tabular}

Table 5 indicated that the changes in quality of life throughout the program phase. It can clearly be seen that, there are significance difference in psychological, spiritual, emotional and social aspects this reported between Damietta group pre/post program. The total score of quality of life in pretest the highly quality among Damietta group and Port Said group were $3.3 \%$ and $10 \%$ respectively after the program they improved among Damietta group 30\% but in port said group not change. And also there was high statistically significant improvement of the posttest in Damietta group more than Port said group $p<.0001$.

Published by Sciedu Press
Table 6 illustrated the correlation matrix among scores of patients' knowledge practices and quality of life between before and after the program. The table indicated statistically significant positive intervention but strong correlation among the three variables, skin care practices, foot care practices and daily activity practices and total practice score were $r=$ $0.520,0.425,0.410,0.466$ respectively. The table indicated the strong being between knowledge and quality of life in variables psychological, emotional and social aspects and total scores were $r=0.456,0.279,0.367$ respectively. 
Table 5. Comparison between Damietta group and Port Said group regarding to quality of life domains

\begin{tabular}{|c|c|c|c|c|c|c|c|c|c|c|c|c|}
\hline \multirow{3}{*}{ Practices } & \multicolumn{4}{|c|}{ Pre-Program } & \multirow{3}{*}{ Sig. } & \multicolumn{4}{|c|}{ Post-Program } & \multirow{3}{*}{ Sig. } & \multirow{3}{*}{$\begin{array}{l}\wedge \text { Sig } \\
\text { Damietta } \\
\text { pre/post }\end{array}$} & \multirow{3}{*}{$\begin{array}{l}\wedge \text { Sig } \\
\text { Port } \\
\text { Said } \\
\text { pre/post }\end{array}$} \\
\hline & \multicolumn{2}{|c|}{$\begin{array}{l}\text { Damietta } \\
(\mathrm{n}=30)\end{array}$} & \multicolumn{2}{|c|}{$\begin{array}{l}\text { Port Said } \\
(\mathrm{n}=20)\end{array}$} & & \multicolumn{2}{|c|}{$\begin{array}{l}\text { Damietta } \\
(\mathrm{n}=30)\end{array}$} & \multicolumn{2}{|c|}{$\begin{array}{l}\text { Port Said } \\
(\mathrm{n}=20)\end{array}$} & & & \\
\hline & No. & $\%$ & No. & $\%$ & & No. & $\%$ & No. & $\%$ & & & \\
\hline \multicolumn{13}{|c|}{ Physical aspects } \\
\hline Poor quality & 30 & 100.0 & 19 & 95.0 & \multirow[t]{2}{*}{${ }^{\mathrm{FE}} p=.155$} & 26 & 86.7 & 18 & 90.0 & \multirow[t]{2}{*}{${ }^{\mathrm{FE}} p=.636$} & \multirow[t]{2}{*}{$p=.112$} & \multirow[t]{2}{*}{$p=1.0$} \\
\hline High quality & 0 & 0.0 & 1 & 5.0 & & 4 & 13.3 & 2 & 10.0 & & & \\
\hline \multicolumn{13}{|c|}{ Sexual aspects } \\
\hline Poor quality & 30 & 100.0 & 20 & 100.0 & \multirow[t]{2}{*}{-NA- } & 29 & 96.7 & 20 & 100.0 & \multirow[t]{2}{*}{${ }^{\mathrm{FE}} p=1.0$} & \multirow[t]{2}{*}{$p=1.0$} & \multirow[t]{2}{*}{-NA- } \\
\hline High quality & 0 & 0.0 & 0 & 0.0 & & 1 & 3.3 & 0 & 0.0 & & & \\
\hline \multicolumn{13}{|c|}{ Psychological/spiritual aspect score } \\
\hline Poor quality & 23 & 76.7 & 16 & 80.0 & \multirow[t]{2}{*}{${ }^{\mathrm{FE}} p=1.0$} & 14 & 46.7 & 14 & 70.0 & \multirow[t]{2}{*}{$p=.103$} & \multirow[t]{2}{*}{$p=.017^{*}$} & \multirow[t]{2}{*}{$p=.465$} \\
\hline High quality & 7 & 23.3 & 4 & 20.0 & & 16 & 53.3 & 6 & 30.0 & & & \\
\hline \multicolumn{13}{|c|}{ Emotional \& social aspects } \\
\hline Poor quality & 21 & 70.0 & 16 & 80.0 & \multirow[t]{2}{*}{$p=.700$} & 12 & 40.0 & 15 & 75.0 & \multirow[t]{2}{*}{$p=.005^{*}$} & \multirow[t]{2}{*}{$p=.020^{*}$} & \multirow[t]{2}{*}{$p=1.0$} \\
\hline High quality & 9 & 30.0 & 4 & 20.0 & & 18 & 60.0 & 5 & 25.0 & & & \\
\hline \multicolumn{13}{|l|}{ Total score } \\
\hline Poor quality & 29 & 96.7 & 18 & 90.0 & \multirow[t]{2}{*}{${ }^{\mathrm{FE}} p=.556$} & 21 & 70.0 & 18 & 90.0 & \multirow[t]{2}{*}{${ }^{\mathrm{FE}} p=.163$} & $p=.006^{*}$ & $p=1.0$ \\
\hline High quality & 1 & 3.3 & 2 & 10.0 & & 9 & 30.0 & 2 & 10.0 & & & \\
\hline
\end{tabular}

Note. -NA-: Not applicable; Significance: $p$ value for Chi-Square or ${ }^{\mathrm{FE}} p$ : $p$ value for Fisher's Exact test; ${ }^{\wedge}$ Sig: $p$ for Mc Nemar test; * ${ }^{*}$ ignificant at $p \leq .05$.

Table 6. Correlation matrix of patients knowledge, practices and quality of life scores between before and after the program

\begin{tabular}{|c|c|c|c|c|}
\hline \multirow{3}{*}{ Practice and quality of life scores } & \multicolumn{4}{|c|}{ Total score of knowledge } \\
\hline & \multicolumn{2}{|c|}{ Before program } & \multicolumn{2}{|c|}{ After program } \\
\hline & $r$ & $p$-value & $r$ & $p$-value \\
\hline \multicolumn{5}{|l|}{ Practices } \\
\hline Skin care practices & 0.185 & .198 & 0.520 & $<.0001 *$ \\
\hline Hand care practices & 0.120 & .405 & 0.114 & .432 \\
\hline Foot care practices & 0.171 & .234 & 0.425 & $.002 *$ \\
\hline Daily activity practices & 0.039 & .786 & 0.410 & $.003^{*}$ \\
\hline Total practice score & 0.172 & .232 & 0.466 & $.001 *$ \\
\hline \multicolumn{5}{|l|}{ Quality of life } \\
\hline Physical aspects & 0.256 & .072 & 0.207 & .149 \\
\hline Sexual aspects & 0.064 & .658 & 0.248 & .082 \\
\hline Psychological aspects & 0.284 & $.046^{*}$ & 0.456 & $.001 *$ \\
\hline Emotional and social aspects & 0.260 & .068 & 0.279 & $.050^{*}$ \\
\hline Total score & 0.349 & $.013 *$ & 0.367 & $.009 *$ \\
\hline
\end{tabular}

Note. $r$ : Pearson correlation coefficient; *significant at $p \leq .05$.

\section{Discussion}

Breast cancer is the most common form of cancer in females worldwide and the most prevalent cancer among Egyptian women. For a long time the focus has been on clinical management of cancer but nowadays Quality of Life is emerging as an important health outcome which requires to be incorporated in the holistic management of patients. In addition Health education program as a viable intervention for the maintenance of health and the prevention of disease has received increasing attention in the last decade (El-Bahlawan 2013, Obrist et al. 2014). ${ }^{[22,24]}$ The goal of most of the edu- cational program is some kind of behavioral change, attitudes and cultural or social barriers to health; promote self-care; develop activities to improve patient participation on clinical processes; educate individuals to protect their health. ${ }^{[25]}$

Regarding the medical and obstetric data, the age of menstruation, the present study findings revealed that the mean age of Damietta group was $13.4 \pm 1.4$ while the mean age of menstruation of Port Said was $11.1 \pm 1.2$. These findings are in agreement with several previous studies ${ }^{[27-30]}$ in which the authors mentioned that mostly sixty-seven percent of the girls were well prepared and aware about menstruation. 
Also, Supportive evidence with a study done in Egypt ${ }^{[22]}$ and study done in Ghana ${ }^{[24]}$ reported that the mean age at menstruation among Egyptian female adolescents was 12.87 \pm 1.29 years. In a study in Mansoura, Egypt 2004, the mean age at menstruation was 12.9 years. While in Alexandria 2004 , the mean age was $11.91 \pm 0.93$ years. In a study Jordanian girls 2004 among the mean age was 13.8 years. This difference could be explained and attributed to the influence of general health by many factors such as genetic factors, socioeconomic, nutritional status and environmental condition.

In addition, the results of the present study showed that, the most of participants was normal in duration, amount, regular and frequency of menstruation. Furthermore, the results indicated that the participants mean age at last menses in group Damietta was $42.6 \pm 5.4$ compared to group Port Said was $44.3 \pm 6.9$. This result could be interpreted by the fact that every woman physiological changes different from other. This results are in agreement with a study done in Saudi ${ }^{[31]}$ which have reported that the majority of women was 79.2\% in Saudia and women in Egypt was 48\%, and also, study done in Egypt ${ }^{[32]}$ was normal frequency and duration of menstruation. Conversely, Zegeye (2009) ${ }^{[33]}$ and El-Lassy \& Madian (2012) ${ }^{[34]}$ have mentioned that one thirds of the women had experienced abnormal menstrual cycle intervals $(<21$ days or $>35$ days). This result may be explained in the light of the fact that the hormonal change is common at this time. In addition, other causes of menstrual irregularity as endocrine disorders, tumors and acquired disorders such as stress.

The findings in Table 3 have revealed that women's knowledge regarding definition, signs and symptoms, precipitating factors, warning signs, factors effecting on health, complications, mastectomy type of therapy after surgery, women condition after medications, effect of treatment, women opinion about compliance, medications, effect of chemotherapy and radiotherapy after mastectomy, status after using treatment, food items taken after mastectomy, food items avoided after mastectomy was incorrect answer before the program. After program implementation there were statistically significant improvement in most aspects of knowledge in both Damietta group was $67.7 \%$ and Port Said group was $25 \%$. This is documented by the increase in the percentage of women who have good knowledge scores this could be explained by the positive impact of the educational program on the mastectomy women's knowledge. Also, it could be explained by the interest of the women of the both groups with the teaching methods and audio visual material used in the educational and the researcher and encouraged them. Implementation of the program was associated with a highly statistically significant improvement in Damietta compared to Port Said group, this may be related appropriate coping strategies to deal with a life threatening disease and may be interested to have an active role in their disease management. This finding is supported with a study done in USA (Springer et al., 2010) ${ }^{[25]}$ and other a study done in Egypt (Mahdy \& Ali 2012) ${ }^{[36]}$ who have indicated that more than half of them received radiotherapy and about two thirds of them received chemotherapy.

In the contrary to this finding, a study done in El-Mansoura, Egypt by El-Khawaga \& Abdel-Wahab (2015) ${ }^{[37]}$ reported that the three quarters of studied patients had correct knowledge about symptoms of disease. These findings are in accordance with many previous studies in many countries like a study done in East and Southeast Asia ${ }^{[38]}$ and a study done in Nepal, ${ }^{[39]}$ also Abdo and Mohamed (2010) ${ }^{[40]}$ found in their study in Zagazig, Egypt, about only one third were knowledgeable. The relatively higher rate of knowledgeable disease in the present work could be explained by higher percentage of educated participants and high rate of positive family history.

Generally, most of the both groups Damietta and Port Said in the present study had poor compliance of practice comprehensive care related to skin care, hands care, foot care and daily activity before the program. After the program implementation, significant improvements were noticed in mastectomy women in comprehensive care. These improvements were noticed in Damietta group more than compared to Port Said group. These findings are in line with the several studies done in Egypt ${ }^{[41,42]}$ who found that the very low levels of adequate practice and no statistically significant difference between the study and control group regarding foot and nail care practice before program implementation. Furthermore, a study done in El-Mansoura, Egypt ${ }^{[27]}$ has emphasized that women after training program led to good adherence to self-care practices as arm care, nutrition and exercise. These findings disagreed with Genga et al.'s (2014) ${ }^{[43]}$ and Abd El Latif1 et al.'s (2016) ${ }^{[44]}$ studies as they reported less than two third of the study group had some employment whether part or full time.

Therefore, the researchers' point of views were that the group Damietta was $86.7 \%$ of the women housewives and unemployed and their low educational level gave them no chance for employment, while slightly less than two thirds (55\%) in Port Said group which means the group Damietta interested by the program.

Concerning quality of life, most the women in the present study had poor health status and high negative impact of mastectomy women on their quality of life dimensions related 
to all aspects such as physical, psychological, emotional and social, sexual and spiritual and moral before the program. After the program implementation, significant improvement in some aspects of quality of life were noticed in the mastectomy women. This results are in agreement with Tsuchiya et al. (2013), ${ }^{[45]}$ Davis et al. (2014) ${ }^{[46]}$ and Williams \& Jeanetta $(2015)^{[47]}$ who have similarly reported that all of their studied patients were negative effects on quality of life and its dimensions. In addition, several studies done in Ethiopia, and India, ${ }^{[48]}$ Bahrain $^{[49,50]}$ also reported that poor quality of life as it is compared to many international findings and attention should be given to improve their QoL. Participants had low role functioning and social functioning. Moreover, no significant association was identified between type and duration of treatment and QoL of participants. ${ }^{[51]}$

As regards physical aspect, the results of the present study revealed that the majority of mastectomy women were poor physical aspect in the pre-program. After the program there was low change in Damietta group was $13.3 \%$ compared to Port Said group was $10 \%$ and there is no statistically significance relationship. This finding was in the same line with Abd El Latif et al. (2016) ${ }^{[43]}$ in Egypt who found that had low QoL in physical health domain. These findings could be explained by the fact that mastectomy women suffering from physical disability, fatigue and general was pain especially shoulder pain. On the contrary to this finding with a study done in Egypt by El-Bahlawan (2013) ${ }^{[22]}$ who found that, $76.4 \%$ of the study group have mild ability to participate in hard activity compared with $81.1 \%$ of subjects have enough energy to do her daily activity post educational program.

Concerning, sexual aspects, the present results have revealed that low change in the only group Damietta group was 3.3\% after the program and there is no statistically significance relationship. These findings are congruence with Denewer et al. (2012) ${ }^{[2]}$ in Egypt who found that $15.1 \%$ of women had been sexually active only and other studied sample was very negative on their sexual feelings and interest. On the contrary to this finding with a study done in Egypt by El-Bahlawan $(2013)^{[22]}$ who found that all married women of the subjects didn't enjoyed with their sexual life preprogram compared with $70.5 \%$ having moderate enjoy with their sexual life post program.

On the other hand, the present results have revealed that the psychological and spirituality aspects was a positive factor in improving changes that had occurred mastectomy women during educational program before and after. Therefore, the researchers point of views that the changes, seen through a renewed sense of faith, were attributed to an improved quality of life. This finding came in agreement with a study done in United states ${ }^{[47]}$ which have supported that spirituality was a positive factor in improving changes that had occurred in lives of breast cancer survivors during treatment and after it.

Regarding to social and emotional function, this result revealed statistically significant improvements in mastectomy women in two groups. These results are in agreement with Hagrass et al. (2012) ${ }^{[52]}$ and El-Bahlawan (2013) ${ }^{[22]}$ have similar found that the low scores social status and emotional well-being, after implementing the education program, all of the studied group their scores increased moreover and became highly improvements of quality of life. This could be attributed to that, direct effective social support and cognitive behavioral adaptation techniques to that disease which conducted and provided from specialized health care providers as well as nursing staff at breast cancer units appeared to play an important role in promote successful coping with disease among those women.

However, after the program intervention, improvements were found in the total scores of. Furthermore, there were statistically significant correlations among knowledge, practice and quality of life scores. These finding are in agreement with Tsuchiya et al. (2013), ${ }^{[45]}$ Davis et al. (2014) ${ }^{[46]}$ and Williams and Jeanetta (2015), ${ }^{[47]}$ Bekele (2016), ${ }^{[26]}$ Muliira et al. (2017). ${ }^{[51]}$ These authors have reported that the positive impact training programs have good effect and improving in knowledge, skills and many aspects of quality of life in breast cancer patients including physical, psychological, social, emotional, and spiritual aspects.

Finally, the present study findings have indicated that evaluation of quality of life and its components in mastectomy women with diabetic and its comparison between Damietta group and Port Said group showed a significant difference in quality of life and its components between breast cancer patients and improvement women; the mean values were significantly higher in post program compared to pre-program. In addition there were improvement in mastectomy women' in the Damietta group knowledge and practice and positive change in quality of life after the implementation of the program more than port Said group. The researcher point of view suggest that, this might be related due to cultural differences in the study areas.

\section{Conclusion}

In the light of the study, it is concluded that, there is a marked gap between knowledge, practice and quality of life among the mastectomy women with diabetic before implement the program. After implementation of the program, considerable improvements were noticed in mastectomy women's knowledge, as well as lifestyle practices. Also there were 
positive changes in quality of life in psychological, spiritual, emotional and social aspects. Furthermore, there were improvement in mastectomy women in the Damietta group knowledge and practice and positive change in quality of life after the implementation of the program more than port Said group. Therefore, the educational program was successful in attaining its aim of positively changing the knowledge, practice and quality of life of mastectomy women

\subsection{Recommendations}

In the light of the main findings of current study the following recommendations are suggested:

(1) Periodical health educational programs should be designed to enhance patient's ability to care for breast cancer with diabetes emphasis on the most important risk factors and appropriate management. Educational programs should be planned and offered on instruction about early diagnosis and breast self-examination practice given by health care stuff and basic knowledge to nurses working on both oncology clinic, to minimize complications especially amputation.

(2) Breast cancer counseling, and close supervision, tremendous amount of support and utilization of the optimum health resources.

(3) Further attentions for women having breast cancer mastectomy and diabetes to improve quality of life through encouraged her to practice normal daily life of activities.

(4) Based on these findings a potential health education sessions needs to be formed to improve the capabilities of community health nurse working in oncology outpatient clinic to competently mastectomy women with diabetes's related to knowledge and practice.

(5) Further researches are needed to evaluate the duration of these improvement in quality of life among mastectomy women with diabetes.

\subsection{Study limitation}

The total sample size were 60 mastectomy women with diabetic from (30 women Port Said and 30 women Damietta) setting, but was 10 cases from in Port Said withdrawal of study sample.

\section{ACKNOWLEDGEMENTS}

The authors would like to express my deepest appreciation and sincere gratitude to everyone who has contributed to this work. In particular The authors would like to thank all the nurses guidance and constant support throughout this study. Without you, this study would not have been accomplished.

\section{CONFLICTS OF INTEREST Disclosure}

The authors report no conflicts of interest. The authors alone are responsible for the content and writing of the paper.

\section{REFERENCES}

[1] Ghoncheh M, Momenimovahed Z, Salehiniya H. Epidemiology, Incidence and Mortality of Breast Cancer in Asia. Asian Pac J Cancer Prev. 2016; 17(S3): 47-52. PMid:27165207 https ://doi .org/10 .7314/APJCP. 2016.17.S3.47

[2] Denewer A, Farouk O, Kotb S, et al. Quality of life among Egyptian women with breast cancer after sparing mastectomy and immediate autologous breast. Breast Cancer Res Treat. 2012; 133: 537-544. PMid:21956212 https://doi.org/10.1007/s10549-011-179 2-8

[3] Torre LA, Bray F, Siegel RL, et al. Global cancer statistics, 2012. CA Cancer J Clin. 2015; 65(2): 87-108. PMid:25651787 https: //doi.org/10.3322/caac.21262

[4] Hasan M, Al Zohairy M, Mohieldein A. Diabetic type 2 and breast cancer marker CA 15.3 value. European Journal of Experimental Biology. 2014; 4(2): 178-181.

[5] Handelsman Y, Leroith D, Bloomgarden ZT, et al. Diabetes and cancer: an AACE/ACE consensus statement. Endocr. Pract. 2013; 19(4): 675-693. PMid:23978590 https : //doi .org/10.4158/EP13248. CS

[6] Karlin NJ, Dueck AC, Cook CB. Cancer with diabetes: prevalence, metabolic control, and survival in an academic oncology practice. Endocr. Pract. 2012; 18(6): 898-905. PMid:22982797 https://doi.org/10.4158/EP12128.OR

[7] Liaw YP, Ko CP, Jan1 RS, et al. Implications of Type1/2 Diabetes Mellitus in Breast Cancer Development: A General Female Population-based Cohort Study. Journal of Cancer. 2015; 6(8): 734 739. PMid:26185535 https://doi.org/10.7150/jca. 12197

[8] Peairs KS, Barone BB, Snyder CF, et al. Diabetes mellitus and breast cancer outcomes: a systematic review and meta-analysis. J Clin Oncol. 2011; 29: 40-6. PMid:21115865 https://doi.org/10.120 0/JC0.2009.27.3011

[9] Cleveland RJ, North KE, Stevens J, et al. The association of diabetes with breast cancer incidence and mortality in the Long Island Breast Cancer Study Project. Cancer Causes Control. 2012; 23: 1193-203. PMid:22674293 https://doi .org/10.1007/s10552-012-998 9-7

[10] Zelenko Z, Gallagher EJ. Diabetes and cancer. Endocrinol. Metab. Clin. North Am. 2014; 43(1): 167-185. PMid:24582097 https: //doi.org/10.1016/j.ecl.2013.09.008

[11] Selvin E, Parrinello CM, Sacks DB, et al. Trends in prevalence and control of diabetes in the United States, 1988-1994 and 1999-2010. Ann Intern Med. 2014; 160(8): 517-525. PMid:24733192 https : //doi.org/10.7326/M13-2411

[12] Liao S, Li J, Wei W, et al. Association between diabetes mellitus and breast cancer risk: a meta-analysis of the literature. Asian Pac J Cancer Prev. 2011; 12: 1061-5. 
[13] Zou Z, Hu J, McCoy PT. Quality of life among women with breast cancer living in Wuhan, China. International Journal of Nursing Sciences. 2014; 79-88. https : //doi .org/10.1016/j.ijnss. 2014 .02 .021

[14] Yan B, Yang LM, Hao LP, et al. Determinants of quality of life for breast cancer patients in Shanghai, China. PLoS ONE. 2016; 11 : e0153714. PMid:27082440 https://doi.org/10.1371/journa 1.pone. 0153714

[15] Quinten C, Martinelli F, Coens C, et al. A global analysis of multitrial data investigating quality of life and symptoms as prognostic factors for survival in different tumor sites. Cancer. 2014; 120: 302-3011. PMid:24127333 https://doi.org/10.1002/cncr. 28382

[16] Ediebah DE, Coens C, Zikos E, et al. Does change in health-related quality of life score predict survival? Analysis of EORTC 08975 lung cancer trial. Br J Cancer. 2014; 110: 2427-33. PMid:24743709 https://doi.org/10.1038/bjc.2014.208

[17] Sharma A, Walker LG, Monson JR. Baseline quality of life factors predict long term survival after elective resection for colorectal cancer. Int J Surg Oncol. 2013; 2013: 269510. PMid:24369498 https://doi.org/10.1155/2013/269510

[18] Trejo-Ochoa JL, Maffuz-Aziz A, Said-Lemus FM, et al. Impact on quality of life with breast reconstructive surgery after mastectomy for breast cancer. Ginecol Obstet Mex. 2013; 81: 510-8.

[19] Canario ACG, Cabral PU, de Paiva LC, et al. Physical activity, fatigue and quality of life in breast cancer patients. Rev. Assoc. Med. Bras. 2015; 62; 38-44. PMid:27008491 https://doi.org/10.1 590/1806-9282.62.01.38

[20] Hamidou Z, Dabakuyo-Yonli TS, Guillemin F, et al. Impact of response shift on time to deterioration in quality of life scores in breast cancer patients. PLoS One. 2014; 9(5): e96848. PMid:24828426 https://doi.org/10.1371/journal.pone.0096848

[21] World Health Organization WHO Quality of Life Assessment Group. What quality of life?/The WHOQOL Group. World Health Forum. 1996; 17(4): 354-356.

[22] El-Bahlawan MAG. Effect of designed educational program on improving the quality of life of women after mastectomy, The Doctorate thesis, faculty of nursing, Port Said University, Egypt. 2013; 32-34.

[23] Ali MM. Informational needs and concerns among women with breast cancer after surgery. Thesis for Master Degree in Nursing Science, Medical-Surgical Nursing, Benha University. 2012; 98.

[24] Obrist M, Ernest OB, Baffour A, et al. Factors related to incomplete treatment of breast cancer in Kumasi, Ghana. The Breast. 2014; 23(6): 821-828. PMid:25282667 https ://doi.org/10.1016/j . breast. 2014.08 .014

[25] Abdel Azeaz M, Taha MN, Hassan A, et al. Effect of Educational Program Regarding Therapeutic Exercises on Women's Pain, Fatigue and Shoulder Function Undergoing Mastectomy. J Am Sci. 2013; 9(3): 412-425.

[26] Bekele AM. Assessing the quality of life of patients with breast cancer at Tikur Anbassa Specialized Hospital, Addis Ababa, Ethiopia. Master thesis in International Social Welfare and Health Policy at Oslo and Akershus University College of Applied Science, Oslo. Norway. 2016; 16-52.

[27] Ei-Gilanya A, Badawi K, El-Fedawy S. Menstrual hygiene among adolescent school girls in Mansoura, Egypt. Reprod. Health Matters. 2005; 13(26): 147-152. https://doi.org/10.1016/S0968-808 0 (05) 26191-8

[28] Khudair F. Assessment the Level of awareness of Female Students toward menstruation in Nursing College Kufa Journal For Nursing. 2013; 3(1): 57-62.

[29] El-Mowafy IR, Moussa MMM, El-EzabyHH. Effect of Health Education Program on Knowledge and Practices about Menstrual Hy- giene among Adolescents Girls at Orphanage Home. IOSR Journal of Nursing and Health Science. 2014; 3(6): 48-55. https: //doi.org/10.9790/1959-03614855

[30] Aburshaid FAH, Ahmad SG, Ashmauey AA, et al. Effect of Planned Health Educational Program on Menstrual Knowledge and Practices among Adolescent Saudi Girls. J Nurs Health Stud. 2017; 2(3): 16.

[31] Karout N. Knowledge and beliefs regarding menstruation among Saudi nursing students. Journal of Nursing Education and Practice. 2016; 6(1): 23-30. https ://doi.org/10.5430/jnep.v6n1p23

[32] Abdelhameed M, et al. Assessment of Dysmenorrhea and Menstrual Hygiene Practices among Adolescent Girls in Some Nursing Schoolsat EL-Minia Governorate, Egypt. Journal of American Sciences. 2011; 7(14).

[33] Zegeye D. Age at menarche and the menstrual pattern of secondary school adolescents in northwest Ethiopia. BMC Women's Health. 2009; 9: 29. PMid:19804623 https ://doi.org/10.1186/1472 $-6874-9-29$

[34] El-LassyBR, Madian AA. Impact of Health Educational Program on Menstrual Beliefs and Practices of Adolescent Egyptian Girls at Secondary Technical Nursing School. Life Sci. J. 2013; 10(2): 335-345.

[35] Springer BA, Levy E, McGarvey C, et al. Pre-operative Assessment Enables Early Diagnosis and Recovery of Shoulder Function in Patients with Breast Cancer. Breast Cancer Res Treat. 2010; 20(1): 135147. PMid:20054643 https://doi.org/10.1007/s10549-009 $-0710-9$

[36] Mahdy EN, Ali SAR. Effect of Pre-discharge Guidelines on Women's Knowledge and Self-Care Practices Regarding Arm Lymphedema Prevention Post mastectomy. J Am Sci. 2012; 8(12): 1003-1017.

[37] El-Khawaga G, Abdel-Wahab F. knowledge, attitude, practice and compliance of diabetic patients in Dakalia, Egypt. European Journal of Research in Medical Sciences. 2015; 3(1): 40-53.

[38] Perez MA, Cha K. Diabetes Knowledge, Beliefs, and Treatments in the Hmong Population: An Exploratory Study. Hmong Studies Journal. 2007; 8: 1-21.

[39] Upadhyay DK, Palaian S, Shankar PR, et al. Knowledge, attitude and practice about diabetes among diabetes patients in western Nepal. Rawal Medical Journal. 2008; 33(1): 8-11.

[40] Abdo MN, Mohamed ME. Effectiveness Of Health Education Program For Type 2 Diabetes Mellitus Patients Attending Zagazig University Diabetes Clinic, Egypt. Egypt Pub Heal Ass J. 2010; 85(3\&4): 113-130.

[41] Mersal FA. Mahday NE and MersaNAl. Efficiency of Web-Based Education versus Counseling on Diabetic Patients' Outcomes. Life Sci J. 2012; 9(3): 912-926.

[42] Mohamed HA, Elsaher HE, Aref MS, et al. The Effect of Diabetic Foot Care Training Program on Elderly Adults' Outcome. IOSR Journal of Nursing and Health Science. 2015; 4(4): 14-20.

[43] Genga E, Otieno C, Ogola E, et al. Assessment of the perceived quality of life of non-insulin dependent diabetic patients attending the diabetes clinic in Kenyatta national hospital. IOSR J Pharm. 2014; 4(3): 15-21.

[44] Abd El Latif FM, Abd El Wahid HA, Mohamed AA, et al. Physical and psychological health domains of the quality of life in type 2 diabetic patients in relation to clinical factors of diabetes mellitus in Egypt. International Research Journal of Medicine and Medical Sciences. 2016; 4(1): 7-16. https://doi.org/10.25141/2471-6 782-2016-4.0152

[45] Tsuchiya M, Horn S, Ingham R. Positive changes in Japanese breast cancer survivors: A qualitative study. Psychology, Health \& Medicine. 2013; 18(1): 107-116. PMid:22646702 https://doi.org/10.1 $080 / 13548506.2012 .686620$ 
[46] Davis C, Myers H, Nyamathi A, et al. The Meaning of Survivorship as Defined by African American Breast Cancer Survivors. Journal of Transcultural Nursing. 2014; 27(3): 1-9. PMid:25480269 https://doi.org/10.1177/1043659614561678

[47] Williams F, Jeanetta S. Lived experiences of breast cancer survivors after diagnosis, treatment and beyond: qualitative study. Health Expectations. 2015; 19(3): 631-642. PMid:25953316 https : //doi.org/10.1111/hex.12372

[48] Dubashi B, Vidhubala E, Cyriac S, et al. Quality of life among young women with breast cancer: Study from a tertiary cancer institute in south India. Indian Journal of Cancer. 2010; 47(2): 142-147. PMid:20448376 https : //doi .org/10.4103/0019-509X . 6300 5

[49] Jassim GA, Whitford DL. Quality of life of Bahraini women with breast cancer: a cross sectional study. BMC Cancer. 2013; 13:
212-212. PMid:23622020 https://doi.org/10.1186/1471-2 407-13-212

[50] Manandhar SDS, Shrestha P, Taechaboonsermsk S, et al. Quality of life among breast cancer patients undergoing treatment in national cancer centers in Nepal. Asian Pac J Cancer Prev. 2014; 15(22): 97537. https://doi.org/10.7314/APJCP.2014.15.22.9753

[51] Muliira RS, Salas AS, O'Brien B. Quality of life among female cancer survivors in Africa: An integrative literature review. Asia Pac J Oncol Nurs. 2017; 4: 6-17. PMid:28217724 https ://doi .org/10 $.4103 / 2347-5625.199078$

[52] Hagrass SAA, Abd Allah ES, Hassan SAA, et al. Improving Quality of Life For Women With Arm Lymphoedema Post Mastectomy in Zagazig City. Australian Journal of Basic and Applied Sciences. 2013; 6(3): 428-442. 